\title{
Gene Therapy Strategies to Exploit TRIM Derived Restriction Factors against HIV-1
}

\author{
Emma Chan ${ }^{1}$, Greg J. Towers ${ }^{2}$ and Waseem Qasim ${ }^{1, *}$ \\ 1 Centre for Gene Therapy, Institute of Child Health, University College London, London WC1N 1EH, \\ UK; E-Mail: emma.chan@ucl.ac.uk \\ 2 MRC Centre for Medical Molecular Virology, University College London, London WC1E 6BT, \\ UK; E-Mail: g.towers@ucl.ac.uk \\ * Author to whom correspondence should be addressed; E-Mail: w.qasim@ucl.ac.uk; \\ Tel.: +44-20-7905-2794; Fax: +44-20-7905-2810.
}

Received: 24 October 2013; in revised form: 20 December 2013 / Accepted: 6 January 2014 / Published: 14 January 2014

\begin{abstract}
Restriction factors are a collection of antiviral proteins that form an important aspect of the innate immune system. Their constitutive expression allows immediate response to viral infection, ahead of other innate or adaptive immune responses. We review the molecular mechanism of restriction for four categories of restriction factors; TRIM5, tetherin, APOBEC3G and SAMHD1 and go on to consider how the TRIM5 and TRIMCyp proteins in particular, show promise for exploitation using gene therapy strategies. Such approaches could form an important alternative to current anti-HIV-1 drug regimens, especially if combined with strategies to eradicate HIV reservoirs. Autologous $\mathrm{CD}^{+} \mathrm{T}$ cells or their haematopoietic stem cell precursors engineered to express TRIMCyp restriction factors, and provided in a single therapeutic intervention could then be used to restore functional immunity with a pool of cells protected against HIV. We consider the challenges ahead and consider how early clinical phase testing may best be achieved.
\end{abstract}

Keywords: HIV; gene therapy; restriction factor; TRIM; cyclophilin; TRIMCyp

\section{Introduction}

Although highly active antiretroviral therapy (HAART) has improved life expectancy of HIV-1 patients, such treatment is far from ideal with notable side effects, problems with compliance and the 
frequent emergence of viral escape mutants. In addition, HAART must be continued for extended periods in most cases. The need for an effective alternative, alongside advancements in gene therapy, has resulted in a large expansion in the field of research for anti-HIV-1 gene therapy. Two broad gene therapy strategies against HIV are under development and a number have reached clinical testing. Firstly, effector cells can be modified using vectors to target and destroy HIV infected cells. For instance, a chimeric antigen receptor formed of the transmembrane and extracellular domains of CD4 fused to the intracellular $\zeta$ subunit of CD3 mediated killing of HIV-1 infected cells by targeting the gp120 envelope (Env) protein and has been evaluated in phase I and II clinical trials [1,2]. Secondly, susceptible cells can be modified to protect them against HIV-1 entry and integration using various mechanisms ranging from zinc finger nucleases targeting the CCR5 virus co-receptor [3,4] to the expression of dominant negative proteins disrupting virus lifecycle [5]. It would be most beneficial to target HIV-1 early in its lifecycle, either at the point of entry or prior to integration, to limit cytotoxic effect, reduce opportunities for mutagenic evolution during reverse transcription and to prevent establishment of latent reservoirs [6]. Preliminary results from clinical trials have provided safety and feasibility data and important information about persistence of engineered cells in vivo [7-9]. In some cases, there are also promising results relating to the efficacy of the treatments, including a survival advantage of modified cells, reduced viral load and improvements in T cell numbers $[5,8,10]$.

Here we describe how natural anti-HIV restriction factors inhibit HIV and consider how these proteins could be adapted, modified and exploited through gene therapy approaches against the virus. Currently identified restriction factors are grouped as follows; APOBEC proteins, tetherin, SAMHD1 and TRIM5 $\alpha$ proteins, and most studies have investigated their activity against retroviruses (Table 1). The most promising for therapeutic approaches appear to be TRIM based factors, and these are considered in detail after discussing alternative factors and their limitations.

Table 1. Summary of anti-HIV restriction factors and their characteristics.

\begin{tabular}{|c|c|c|c|c|}
\hline Restriction Factor & Mechanism & Viral evasion & Disadvantages & Exploitation \\
\hline APOBEC & $\begin{array}{l}\text { Cytidine deamination } \\
\text { of viral genome }\end{array}$ & $\begin{array}{l}\text { Vif mediated } \\
\text { proteasomal } \\
\text { degradation }\end{array}$ & $\begin{array}{l}\text { APOBEC3G } \\
\text { induced mutations } \\
\text { may promote } \\
\text { evolution of HIV }\end{array}$ & $\begin{array}{c}\text { Modified APOBEC3G } \\
\text { restricts HIV in T cells and } \\
\text { macrophages }[11]\end{array}$ \\
\hline SAMHD1 & $\begin{array}{l}\text { dNTP } \\
\text { triphosphohydrolase } \\
\text { activity depletes } \\
\text { dNTPs and prevents } \\
\text { reverse transcription }\end{array}$ & $\begin{array}{l}\text { HIV-2 Vpx } \\
\text { causes } \\
\text { proteasomal } \\
\text { degradation }\end{array}$ & $\begin{array}{l}\text { Antiviral function } \\
\text { limited to quiescent } \\
\text { cells }\end{array}$ & Undefined \\
\hline Tetherin & $\begin{array}{l}\text { Prevents HIV release } \\
\text { by anchoring budding } \\
\text { virus particles }\end{array}$ & $\begin{array}{l}\text { Lysosomal } \\
\text { degradation is } \\
\text { promoted by } \mathrm{Vpu}\end{array}$ & $\begin{array}{c}\text { Reduces, but does } \\
\text { not abolish spread of } \\
\text { virus.or } \\
\text { establishment of } \\
\text { reservoirs }\end{array}$ & $\begin{array}{l}\text { Vpu resistant tetherin in cell } \\
\text { lines }[12]\end{array}$ \\
\hline $\begin{array}{l}\text { TRIM5 } \alpha / \\
\text { TRIMCyp }\end{array}$ & $\begin{array}{l}\text { Targets virus for } \\
\text { proteasomal } \\
\text { degradation and } \\
\text { disrupts uncoating }\end{array}$ & $\begin{array}{l}\text { HIV-1 accessory } \\
\text { proteins are unable } \\
\text { to counteract } \\
\text { TRIM restriction }\end{array}$ & $\begin{array}{l}\text { Species specific } \\
\text { restriction; human } \\
\text { TRIM5 } \alpha \text { does not } \\
\text { restrict HIV-1 }\end{array}$ & $\begin{array}{c}\text { Chimeric TRIM5 } \alpha \text { and } \\
\text { humanised TRIMCyp } \\
\text { restriction demonstrated in } \\
\text { humanised mice }[13,14]\end{array}$ \\
\hline
\end{tabular}




\section{Innate Immunity against HIV}

Higher organisms have evolved a complex immune system where innate immunity acts rapidly after infection to provide protection against pathogens, allowing time for the adaptive immune system to mount a response. The innate system includes interferon (IFN), pattern recognition receptors (PRR) and secreted soluble molecules such as toll-like receptors or complement.

One aspect of the innate immune system involves the expression of a variety of antiviral restriction factors. These proteins typically involve low levels of constitutive expression allowing a response immediately upon viral infection, although expression is often upregulated following IFN stimulation after viral infection. Independence from cell signaling or cell-cell interaction results in a rapid, first line of defence against invading viruses. Identified restriction factors differ greatly in structure, but have all been subjected to high levels of survival selection during a process of continual evolution alongside relevant viral pathogens. Targets and mechanisms of viral restriction vary between these factors and are generally independent of other cellular processes, not requiring complex signaling pathways to elicit responses in contrast to many other branches of the immune system $[15,16]$. The expression of restriction factors is far more widespread than initially thought and a broad range of mammals have now been shown to express these proteins as a defence against many different viruses [17-20]. Typically HIV-1, HIV-2 and SIV are not significantly inhibited by restriction factors of their natural host species as through necessity these viruses have developed circumventing mechanisms throughout evolution.

Viral infectivity factor (Vif) is critical for HIV-1 infection in certain cell types, including $\mathrm{CD}^{+}{ }^{+} \mathrm{T}$ cells [21]. Resistance against Vif-deficient HIV-1 is mediated by the apolipoprotein B mRNA-editing catalytic polypeptide-like 3 (APOBEC3) family [22]. APOBEC3G is an enzyme capable of mutating DNA by cytidine deamination [23] and contains $N$ - and $C$-terminal cytidine deaminase domains, which mediate RNA binding and sequence specific cytidine deamination of single stranded DNA (ssDNA). Mutation of APOBEC $3 \mathrm{G}$ catalytic sites leads to a loss of restriction, demonstrating that it functions, at least in part, by editing the viral genome using this activity [24,25]. APOBEC3G is incorporated into the core of Vif deficient virions through interactions with both Gag, specifically the nucleocapsid [26], and viral RNA [27]. Once the virion infects a new cell, APOBEC3G remains associated with the mature viral proteins and RNA to enable deamination during reverse transcription. APOBEC3G also inhibits Vif deficient HIV-1 in a deaminase independent way as mutants with a nonfunctional cytidine deaminase domain are still capable of causing significant restriction [28].

Both mouse and African green monkey (agm) APOBEC3G are resistant to HIV-1 Vif and thus mutant APOBEC3G proteins that are resistant to Vif induced proteasomal degradation could be exploited in anti-viral strategies. This species specificity has been mapped to a single amino acid in APOBEC3G, and mutation of the aspartic acid residue at position 128 in human APOBEC3G for lysine renders it resistant to HIV-1 Vif [29,30]. A variation of this Vif resistant APOBEC3G modification is the fusion of human APOBEC $3 \mathrm{G}$ to a $\mathrm{Vpr}$ derived peptide, efficiently targeting it into assembling virions. Despite this modified APOBEC3G still being susceptible to Vif induced proteasomal degradation, the mutant protein is incorporated into virion particles whereupon infectivity is greatly reduced in target $\mathrm{T}$ cells $[11,31]$. 
However, whilst exploitation of APOBEC3G drew initial interest for gene therapy investigators, further studies revealed its interactions with HIV-1 to be highly complex. There is evidence to suggest that sequence mutations induced by APOBEC may actually be beneficial to the virus by promoting drug resistance and evolution. Thus drug resistance mutations develop in HIV-1 in the presence of APOBEC3G in vitro [32]. Furthermore, mutant Vif forms that are less able to inhibit APOBEC3G, may be linked to certain protease and reverse transcriptase mutations that confer additional drug resistance [33].

In 2008, two groups identified tetherin (CD317) as a cell-surface protease sensitive restriction factor $[34,35]$. Tetherin is a type II membrane glycoprotein that inhibits the release of many enveloped viruses, including HIV-1. It functions as a broad specificity restriction factor as it interacts with the host membrane rather than a viral factor [36]. Originally identified on B cells, tetherin has now been shown to have a broad expression pattern, albeit limited in healthy $\mathrm{CD} 4{ }^{+} \mathrm{T}$ cells, dendritic cells and macrophages [37]. HIV-1 normally expresses the accessory protein Vpu, which can abrogate both tetherin induced accumulation of viral particles at the cell surface and NFkB signaling. Vpu is thought to abrogate tetherin through endosomal trafficking and subsequent lysosomal degradation, which requires the host protein $\beta \operatorname{TrCP}[38,39]$. In addition, $\mathrm{Vpu}$ can abolish tetherin mediated restriction without decreasing cellular levels of the protein.

High levels of vector mediated tetherin may be able to saturate Vpu resulting in HIV-1 restriction [40] or Vpu resistant protein variants capable of inhibiting HIV-1 release [12] could potentially be used in gene therapy approaches. However, at best, tetherin based approaches will reduce spread of HIV-1 in modified cells but will not lead to elimination of the virus. Mutant strains deficient in Vpu are likely to be rapidly selected out by positive selection or there may be the evolution of protective proteins seen in other lentiviruses, such as HIV-2 and SIV [41-43].

Another factor, Sterile alpha motif and histidine/aspartic acid domain containing protein-1 (SAMHD1) was originally identified as a protein associated with Aicardi-Goutières syndrome, an encephalopathic condition that manifests in early childhood [44]. Subsequently, SAMHD1 was found to be an HIV-1 restriction factor and in dendritic cells, macrophages and quiescent $\mathrm{CD}^{+}{ }^{+}$cells [45-48].

SAMHD1 functions as a dNTP triphosphohydrolase [49] and has been shown to lower dNTP levels sufficiently to prevent reverse transcription [50]. It consists of a conserved $\mathrm{N}$ terminal SAM domain and a catalytic HD domain responsible for dNTP triphosphohydrolase activity and nuclease activity against ssRNA, ssDNA and RNA in RNA/DNA hybrids [49,51,52]. Despite providing protection to myeloid cells and resting $\mathrm{CD}^{+}{ }^{+} \mathrm{T}$ cells, SAMHD1 is also expressed in other cell types, including actively dividing $\mathrm{CD}^{+} \mathrm{T}$ cells, but only exhibits antiviral activity in non-cycling cells due to a difference in phosphorylation status $[53,54]$. This is likely to limit therapeutic strategies likely to be directly successful in actively dividing $\mathrm{T}$ cells.

In 2004, the cytoplasmic body component TRIM5 $\alpha$ was identified as the restriction factor responsible for the resistance of Old World monkeys against HIV-1 [55]. Shortly after this discovery, TRIM5 $\alpha$ was confirmed to be responsible for the antiviral activities previously accounted for by Ref1 and Lv1 [56,57], restriction factors identified in humans and primates respectively [58-63]. TRIM5 $\alpha$ is a member of the large family of TRIM proteins, which has around 100 human proteins with diverse roles. This family is characterised by its TRIpartite Motif (TRIM), which consists of a RING, B-box and coiled coil (RBCC) domains. In addition to the RBCC domains, the longest splice variant, 
TRIM5 $\alpha$, also includes a C terminal B30.2 or PRYSPRY domain (Figure 1). It is the B30.2 domain that is responsible for binding of restricted virus capsid (CA) and therefore the proteins specificity [64-68]. Typical of antiviral restriction factors, regions within the B30.2 domain have been subject to high levels of positive selection [69] suggesting co-evolution with viruses, with each providing selective pressure on the other to gain the advantage. Throughout evolution it is possible that TRIM5 $\alpha$, with its varying specificity between species, may have played an important role in the control of cross-species transmission of retroviruses [70]. Subsequently, antiretroviral TRIM5 $\alpha$ proteins have been identified in other non-primate species, including rabbit [71], cattle [19,20] and hare [72] and restrict various retroviruses in a species specific manner.

Figure 1. RING, B-Box and coiled coil domains characteristic of TRIM proteins are shown in schematics of TRIM5 $\alpha$ and TRIMCyp proteins. In primate TRIMCyp proteins, the B30.2 domain of TRIM5 $\alpha$, which is responsible for capsid recognition, has been replaced with CypA.

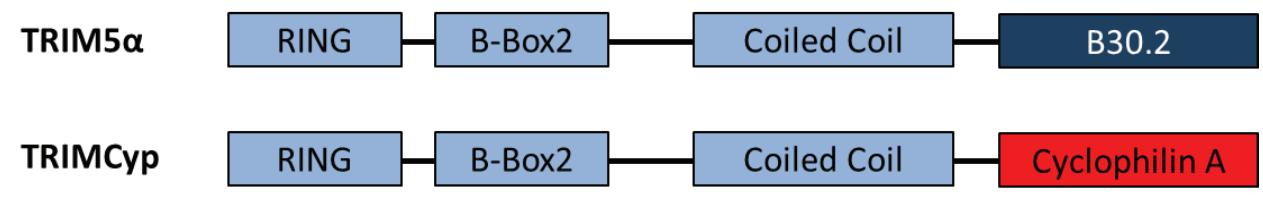

TRIM5 is ubiquitously expressed in all tissues throughout the human body, including T cells [73,74] and while expression levels may be constitutively low, it is upregulated by IFN through a putative IFN-stimulated response element (ISRE) [75]. Restriction patterns are variable between species. For example, TRIM5 $\alpha$ from Rhesus macaque (rhTRIM5 $\alpha$ ) is a strong inhibitor of HIV-1, but not SIVmac, whereas in humans $\mathrm{N}$-tropic murine leukaemia virus (N-MLV) and equine infectious anaemia virus (EIAV) are strongly restricted. Human TRIM5 $\alpha$ (huTRIM5 $\alpha$ ) mediates mild restriction of HIV-2 [76], but does not cause a significant inhibition to HIV-1. These species specific differences in restriction are attributed to CA sequence variation between viruses and subsequently, the ability of TRIM5 $\alpha$ to recognise and bind the virus. Alteration of CA amino acid 110 alters specificity of huTRIM5 $\alpha$ between B- and N-tropic MLV [77]. There are even different restriction specificities within species, for example in Rhesus macaques there are different TRIM5 alleles which have activity against different retroviruses. Throughout evolution, selective pressure from viral infection has driven diversity in the TRIM5 gene [78,79], although in man, TRIM5 $\alpha$ with or without various polymorphisms has little inhibitory effect on HIV-1 infection or disease progression [80-82]. Human TRIM5 $\alpha$ can be modified to provide specificity against HIV-1. Either substitution with critical rhTRIM5 $\alpha$ B30.2 sequences [83] or a single amino acid change at 332 of the human protein is sufficient to activate restriction of HIV-1 $[66,67,84]$. Although HIV-1 is not susceptible to restriction by native hTRIM5 $\alpha$, unlike the other restriction factors mentioned here, the virus has no accessory protein that is able to counteract the restrictive effects of TRIM5 $\alpha$, making it an ideal candidate for gene therapy approaches against HIV.

TRIM5 $\alpha$ inhibits HIV-1 early in infection, as shown by the absence of reverse transcripts after viral entry [77]. However, the detailed processes by which TRIM5 $\alpha$ restricts retroviruses have not been fully determined, although it is likely that TRIM5 $\alpha$ mediates restrictive effects through multiple mechanisms (Figure 2). Upon viral entry of a cell, TRIM5 $\alpha$ recognises CA via its B30.2 domain, 
although the interaction between monomers of these two proteins is weak [85]. TRIM5 $\alpha$ forms dimers which then spontaneously form hexamers, but this is greatly enhanced in the presence of incoming viral CA. Hexamers are required for efficient restriction and mediate more efficient CA binding with higher avidity by allowing multiple B30.2 domains to cover and interact with the incoming viral core [86]. Binding by TRIM5 $\alpha$ in the cytoplasm can lead to accelerated and disrupted uncoating of the virus, preventing infection as this process is normally tightly regulated [87-90]. Autoubiquitinylation and subsequent proteasomal degradation of TRIM5 $\alpha$ requires its RING and B-box domains and it is thought that there is also proteasomal degradation of the TRIM5 $\alpha$-virus complex [91]. Inhibition of the proteasome permits formation of viral reverse transcripts and pre-integration complexes, but these are not detectable in the nucleus. Therefore proteasome inhibition rescues reverse transcription, but does not abrogate the antiviral activity of TRIM5 $\alpha$ [91-93]. Proteasome independent antiviral pathways are likely to involve sequestering of the viral genome within pre-existing aggregations of TRIM5, or by formation of new aggregates around virus particles. TRIM5 $\alpha$ can also be seen to leave cytoplasmic bodies to interact with nearby virus within the cytoplasm [94] and varies between localisation in cytoplasmic bodies and more diffuse distribution throughout the cytoplasm [95]. However, disruption of cytoplasmic bodies with geldanamycin does not prevent restriction, therefore their formation is not essential [96,97]. Recently human and Rhesus TRIM5 $\alpha$ have been shown to shuttle between the cytoplasm and nucleus, and inhibition of CRM1 nuclear export machinery results in accumulation of TRIM5 $\alpha$ in the nucleus. This is not seen in TRIM5 $\alpha$ from cattle, New World monkeys or TRIMCyp [98]. Accumulation of TRIM5 $\alpha$ in the nucleus does not abrogate TRIM5 mediated retroviral restriction, although it is likely that residual cytoplasmic protein or newly synthesised TRIM is responsible for restriction. The relevance of nuclear shuttling of TRIM5 $\alpha$ is not known, and the protein may have additional undefined functions.

In addition to CA recognition, TRIM5 $\alpha$ plays a role in cell signaling in innate immunity. Human TRIM5 $\alpha$ and its murine paralog, TRIM30, downregulate NFKB signaling through proteasome independent degradation of TAB2, an adaptor protein upstream of NFkB. In contrast, human and Rhesus TRIM5 $\alpha$ are able to activate NFkB expression. The activity of these two opposing effects upon $\mathrm{NF \kappa B}$ by the human protein is thought to depend upon TRIM5 $\alpha$ levels [99]. For activation of NFkB signaling, TRIM5 $\alpha$ functions in conjunction with UBC13-UEV1A, an ubiquitin-conjugating enzyme. Together they assemble unattached K63-linked ubiquitin chains that activate the TAK1 kinase complex. TAK1 subsequently stimulates AP-1 and NFKB transcription factors involved in innate immune signaling [100]. The formation of ubiquitin chains and activation of NFKB signaling is significantly enhanced upon $\mathrm{CA}$ recognition. Prevention of formation of these chains through knockdown of UBC13 or UEV1A abrogates huTRIM5 $\alpha$ restriction of susceptible retroviruses, such as EIAV. Through this function, TRIM5 $\alpha$ and TRIMCyp act as pattern recognition receptors as recognition of a restricted retroviral $\mathrm{CA}$ enhances the activation of $\mathrm{NF \kappa B}$ signaling and innate immune responses [100]. 
Figure 2. Schematic showing TRIM5 $\alpha$ restriction of virus within a cell. TRIM $5 \alpha$ is autoubiquitinylated by its RING domain and when virus enters the cell TRIM5 $\alpha$ binds viral capsid via its B30.2 domain, targeting the virus for proteasomal degradation. This block to infection occurs prior to reverse transcription. If cells are treated with MG132 to inhibit the proteasome, reverse transcription occurs and the virus is not degraded, but infection is not rescued. This suggests alternative proteasomal independent antiviral mechanisms.

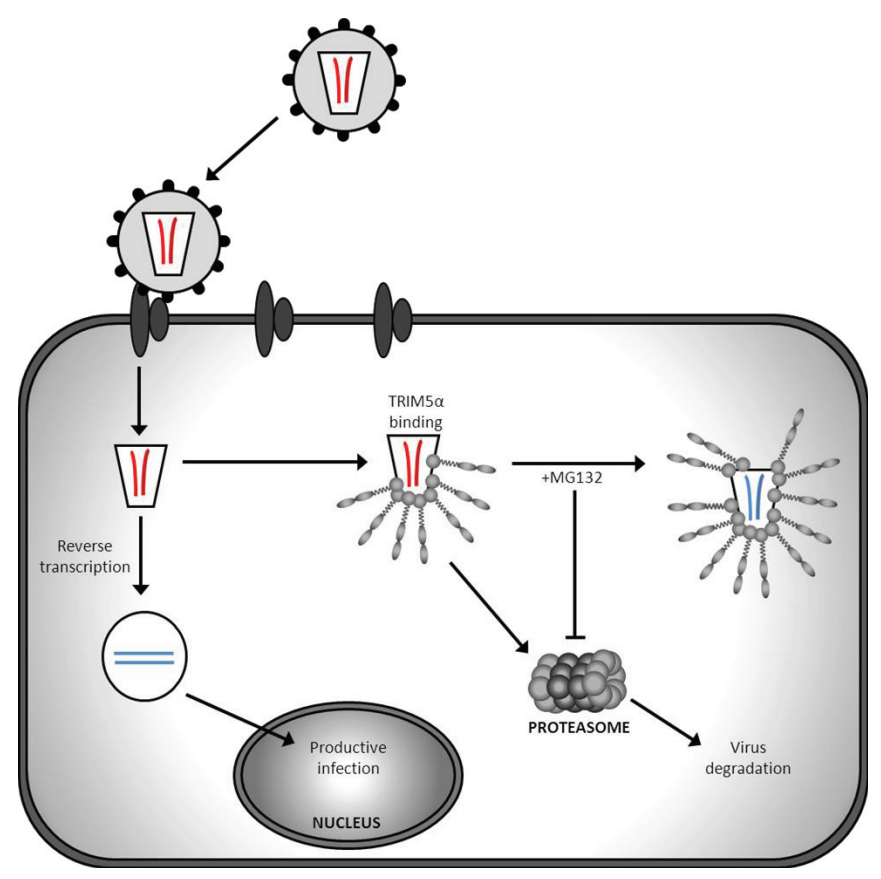

Another protein that interacts with HIV-1 is the peptidyl-prolyl isomerase (PPIase), cyclophilin A (CypA), which catalyses the switch between cis and trans conformations of proline residues. CypA interacts with HIV-1 CA at the G89-P90 peptide bond located on a nine amino acid flexible loop (P85-P93), and catalyses isomerisation of the bond [101,102]. This bond is primarily found in the trans conformation (86\%) [103].Mutation of either G89 or P90 abrogate CypA binding and in addition, the surrounding residues P85, V86, H87, A88, P93 are also involved in binding [104]. CA interaction results in incorporation of CypA into HIV-1 virions and can be prevented by treatment of producer cells with the immunosuppressive drug cyclosporine A (CsA), which is a competitive inhibitor of CypA, mutation of G89-P90 within the CA or knockdown of the CypA gene. In humans, inhibition of this interaction causes a block to HIV-1 infection soon after cell entry [104-107], although it is the presence of CypA in target cells, rather than in producer cells, that is required for optimal infection [108,109]. In addition to HIV-1, SIVagm and FIV have also been shown to recruit CypA [110-112]. CypA acts upon incoming HIV-1 particles soon after entry and before reverse transcription, at the same time as TRIM5 $\alpha$ restriction in non-human primates occurs [113]. CypA has been proposed to have a role in regulating CA uncoating [114]. Also, as CypA causes a range of effects on infectivity, both cell type and species specific, it suggests that other proteins are involved in the interaction between CA and CypA; CypA may provide protection from restriction or make the CA more recognisable to restriction factors such as TRIM5 $\alpha$ through isomerisation [115]. In general, disruption of the CypA-CA interaction leads to HIV-1 restriction in human cells but this effect is both 
strain specific and TRIM5 $\alpha$ allele specific [116,117]. Therefore the function of CypA in HIV-1 infection is complicated, even more so because its effect upon lentiviral infection is species specific, as unlike HIV-1 infection of human cells, in many non-human primate cells the CypA-CA interaction actually enhances TRIM5 $\alpha$ mediated restriction. CypA mediated CA isomerisation may increase binding affinity of TRIM5 $\alpha$ [118,119] or stabilise the CA core prolonging time for recognition by TRIM5 $\alpha$. Most recently, CypA has been shown to have a role in protecting HIV-1 from being detected by the cytoplasmic innate immune DNA sensor cGAS [120]. The HIV-1 CypA binding mutant HIV-1 CA P90A was shown to trigger cGAS in monocyte derived macrophages (MDM) leading to activation of a cell autonomous innate immune response. HIV-1 CA P90A infection of MDM led to production of the second messenger cGAMP, NFkB and IRF3 nuclear localization and production of soluble type 1 IFN, which completely suppressed HIV-1 replication. The importance of IFN in suppressing viral infection was illustrated by rescuing viral replication by blockade of the IFN receptor with specific antibody. The details of how CypA prevents HIV-1 DNA from triggering cGAS remain incompletely described but CypA's role in recruiting HIV-1 into a specific pathway of nuclear entry involving DNA synthesis in complex with the nuclear pore mediated by interactions between viral proteins and Nup358, TNPO3, CPSF6 and Nup153 is likely to be important [120-122].

New World owl monkeys of the genus Aotus express an anti-HIV-1 fusion protein comprising the TRIM5 RBCC domain fused to CypA. The fusion has arisen from LINE-1 (L1) mediated retrotransposition of a CypA cDNA into TRIM5 intron 7. This results in an in-frame fusion between exons 2 to 7 of TRIM5 with CypA cDNA, which replaces the B30.2 domain encoded by exon 8 (Figure 1). Owl monkeys are homozygous for this altered gene and do not encode any other TRIM5 alleles. The owl monkey TRIM5-CyclophilinA (omTRIMCyp) fusion protein is a strong inhibitor of HIV-1, due to the ability of CypA to bind HIV-1 CA and recruit the TRIM5 RBCC domains, and is responsible for the resistance of owl monkey cells to this virus. Inhibition can be overcome by treatment with CsA or the use of G89V HIV-1 mutants [123,124]. omTRIMCyp also restricts FIV and SIVagm, but leaves cells from this species susceptible to infection by SIVmac [110]. There has been another incident of retrotransposition of CypA into the TRIM5 locus of Old World macaques species, including rhesus macaques (Macaca mulatta), pig-tailed macaques (Macaca nemestrina) and crab eating macaques (Macaca fascicularis). This second example of a TRIM-Cyp chimera is most likely to have occurred independently of the owl monkey event due to the different location of the CypA coding sequence, with respect to its position in owl monkeys in the TRIM5 gene, downstream of exon 8 in Old World monkeys [125-128]. The resultant protein is encoded by exons 2 to 6 of TRIM5, with the CypA cDNA replacing exons 7 and 8, in contrast to the owl monkey fusion that is encoded by exons 2 to 7 of TRIM5 and the CypA cDNA (Figure 3). The antiviral specificity of this fusion protein is also distinct to the owl monkey, with the rhesus TRIMCyp being a strong inhibitor of HIV-2, HIV-1 group $\mathrm{O}$ and FIV, but not HIV-1 group M. This difference in restriction specificity is due to variations in the CypA domain of rhTRIMCyp compared to that of the genomic CypA, altering the conformation of the active site loop [129]. Furthermore, TRIMCyp alleles from different macaque species also have different antiviral specificities due to additional mutations in their Cyp domains [130]. Further analysis of TRIM5 and CypA genes throughout primate evolution has identified two additional TRIMCyp genes in rhesus macaques, one of which is still expressed in certain Old world monkey species, although as a non-functional protein. These incidences of convergent evolution to produce TRIMCyp 
restriction factors on more than one occasion and their maintenance in the genome suggests that they experienced strong selective pressure throughout evolution, likely from lentiviral infection [131]. The observation that HIV-1 mutants that do not recruit CypA trigger a cell autonomous innate immune response through activating the DNA sensor cGAS may explain why TRIMCyp chimeras are particularly effective in restricting primate lentiviruses [120].

Despite the differences in specificity of the macaque and owl monkey TRIMCyp proteins, the mechanism of restriction is similar, causing a block in infection before reverse transcription which can be abrogated by CsA treatment or mutation of the TRIMCyp binding site on the viral CA. As with TRIM5 $\alpha$, the mechanism of antiviral restriction is not fully understood, but it is also likely to function through multiple antiviral activities including proteasome recruitment and innate signaling responses. Restriction occurs rapidly after viral entry into the cell before reverse transcription. Although TRIMCyp forms cytoplasmic bodies, they are not essential for restriction [96]. Deletion of the RING domain causes a reduction, but not loss of restriction, suggesting proteasome independent mechanisms, and deletion of the RING and B-Box2 domains eliminates restriction [110] implying that they are important for efficient inhibition. Like TRIM5 $\alpha$, TRIMCyp forms multimers, and dimers, trimers and hexamers have all been identified and TRIMCyp has been shown to disrupt CA cylinders in vitro, suggesting antiviral activity through interference with uncoating [89].

Figure 3. Schematic of TRIM5 and TRIMCyp genes. CypA cDNA retrotransposition into the TRIM5 gene of primates has occurred more than twice throughout evolution to produce in frame fusions of TRIM5 and CypA, with CypA replacing the B30.2 domain. (A) Native TRIM5 gene; (B) In owl monkeys, CypA insertion in intron 7 produces a TRIMCyp protein consisting of exons 2-7 with CypA replacing exon 8; (C) In macaques, CypA is downstream of TRIM5 and accompanied by a mutation leading to skipping of exons 7 and 8 . The resultant protein is encoded by exons 2-6 followed by CypA. Untranslated exons shown in black, translated exons in blue, cyclophilin A (CypA) in red.

A. $\operatorname{TRIM5\alpha }$

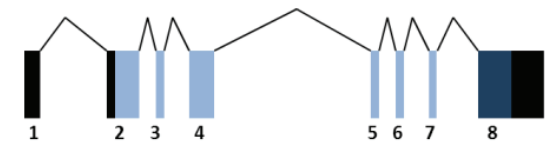

B.

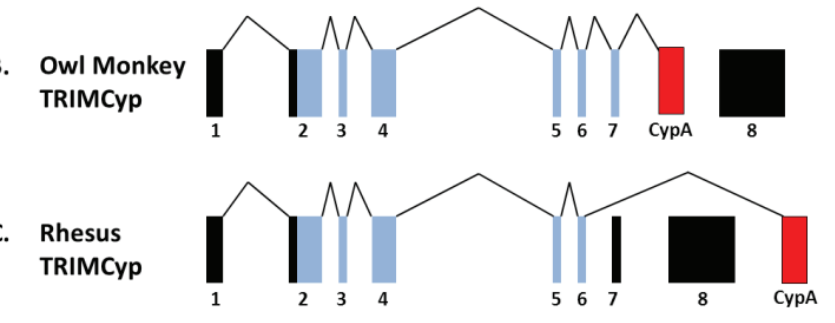

\section{Gene Therapy Exploitation of TRIMCyp Factors}

Human mimics of TRIMCyp are able to restrict HIV-1 and confer a survival advantage at levels comparable to the owl monkey fusion protein when expressed in cell lines, primary $\mathrm{T}$ cells and macrophages. Delivery of these modified $\mathrm{CD}^{+} \mathrm{T}$ cells into an experimental humanised mouse model of HIV-1 showed engraftment of TRIMCyp expressing cells and robust restriction of HIV-1 [13]. 
Humanised mouse models have also been utilised to investigate human $\mathrm{CD} 34^{+}$haematopoietic stem cells (HSCs) transduced with vectors to express chimeric rhesus/human TRIM5 $\alpha$. TRIM5 $\alpha$ expressing cells successfully engrafted and gave rise to multilineage progenitors, which were able to protect against challenge with HIV-1 and also showed a survival advantage during infection [132].These chimeric mouse models provide important evidence supporting the use of TRIM5 based gene therapy strategies in clinical trials.

Similar to Neagu et al., we have reported similar TRIM5 and CypA fusion constructs and have also described fusions between TRIM21 and CypA, which elicit potent anti-HIV effects [133]. TRIM21 mediates activation of NFKB signaling pathways and the B30.2 domain of TRIM21 is a highly efficient $\mathrm{IgG}$ receptor capable of recognising antibody coated virus particles within the cytoplasm and targeting them for proteasomal degradation [134]. After binding to the Fc domain of antibody, the TRIM21 RING domain synthesises K63-linked ubiquitin chains triggering NFkB signaling leading to an antiviral state [135]. These signaling properties are retained in cells transduced to express TRIM21Cyp, suggesting the protein could form the basis of an anti-HIV gene therapy without disrupting endogenous pathways. In addition, TRIMCyp fusion proteins have been generated using alternative TRIM proteins with the same domain structure as TRIM5, including TRIM1, 18 and 19 [136]. Similarly, CypA has been fused to the murine restriction factor Fv1 (Friend virus susceptibility gene 1), retargeting its antiviral specificity from murine leukaemia virus to produce an inhibitor of HIV-1 [137]. A key feature of TRIMCyp based strategies relates to the reduced likelihood of mutagenic escape as the CypA binding loop is highly conserved amongst primate lentiviruses, [110]. Mutation of the CypA binding loop interferes not just with binding of CypA, but also the nuclear pore protein Nup358, which is involved in nuclear import. Disrupting these interactions through mutation of the CypA binding loop affects the site of integration and subsequently viral replication [121]. Therefore, for productive viral infection, maintenance of CypA binding is critical and any escape mutants avoiding TRIMCyp binding are likely to exhibit reduced viral fitness. This appears to be particularly true in macrophages where HIV-1 mutants that do not recruit CypA trigger the DNA sensor cGAS leading to a potent cell autonomous innate immune response that completely suppresses replication [120]. Thus not only will TRIMCyp escape mutants be unfit through an inability to recruit Nup358, they are likely to trigger antiviral and inflammatory cytokine production that will help limit wild type HIV-1 replication in T cells.

Lentiviral delivery of the most promising TRIMCyp offers the prospect of rapid first in man assessment of therapeutic strategies using restriction factors. Phase 1 studies are being planned to investigate the efficiency of gene transfer, engraftment potential and the possibility of host mediated immunes response raised against any novel epitopes formed at the junction between TRIM and CypA. These initial safety studies will transduce and re-infuse autologous $\mathrm{T}$ cells and if successful, subsequent therapies will target autologous HSC. Stem cell based approaches will require preparative chemotherapy similar to that used in recent autologous lentiviral mediated gene correction of inherited immune and metabolic conditions [138,139]. Such myeloablation is essential to secure stem cell engraftment and in the context of HIV, may also help eradicate the host lymphoid and myeloid populations that act as a reservoir for HIV. Recent experience from allogeneic stem cell transplantation in patients with HIV-1 supports this premise [140], and whereas transplant based approaches require human leukocyte antigen-matched, CCR5 null donors, an autologous stem cell modification approach 
will have much wider applicability. Furthermore, if immunity is reconstituted with cells expressing TRIMCyp, both CCR5 tropic and CXCR4 tropic viruses should be restricted.

For stem cell modification, regulated expression of TRIMCyp would be desirable to avoid toxicity and reduce the risk of insertional mutagenesis. Vectors using internal promoter elements derived from TRIM5 regulatory sequences are under investigation, as are strategies to target TRIMCyp insertion into the endogenous TRIM5 locus. These approaches should result in IFN-inducible TRIMCyp expression in CD4 expressing macrophages and post thymic T cells following exposure to HIV.

Finally a number of logistical challenges need to be addressed before these approaches can be investigated in man, including the production of clinical grade vector stocks and optimization of ex vivo transduction protocols. Nonetheless, there is a compelling rationale to pursue these approaches as supported by encouraging data from other $\mathrm{T}$ cell and stem cell gene therapies.

\section{Conclusions}

Despite showing natural ability to restrict certain strains of HIV-1, most identified restriction factors are effectively counteracted by viral accessory proteins. TRIM5 $\alpha$ and related TRIMCyp proteins hold the greatest promise for gene therapy applications. Expression of these proteins using lentiviral vectors should protect modified cells through mechanisms that do not appear to be abrogated by any viral countermeasure.

Early phase clinical trials are planned to investigate the feasibility of TRIMCyp based therapies, and in the first instance will involve ex vivo modification and re-infusion of autologous $\mathrm{T}$ cells, followed by studies in autologous HSC once feasibility and safety data is established.

\section{Acknowledgments}

The authors receive support from Great Ormond Street Hospital Children's Charity, Wellcome Trust, Rosetree Trust and National Institute of Health Research via UCL/UCLH/GOSH Comprehensive Biomedical Research Centres.

\section{Conflicts of Interest}

The authors declare no conflict of interest.

\section{References and Notes}

1. Mitsuyasu, R.T.; Anton, P.A.; Deeks, S.G.; Scadden, D.T.; Connick, E.; Downs, M.T.; Bakker, A.; Roberts, M.R.; June, C.H.; Jalali, S.; et al. Prolonged survival and tissue trafficking following adoptive transfer of CD4zeta gene-modified autologous $\mathrm{CD} 4^{+}$and $\mathrm{CD} 8^{+} \mathrm{T}$ cells in human immunodeficiency virus-infected subjects. Blood 2000, 96, 785-793.

2. Deeks, S.G.; Wagner, B.; Anton, P.A.; Mitsuyasu, R.T.; Scadden, D.T.; Huang, C.; Macken, C.; Richman, D.D.; Christopherson, C.; June, C.H.; et al. A Phase II randomized study of HIV-specific T-cell gene therapy in subjects with undetectable plasma viremia on combination antiretroviral therapy. Mol. Ther. 2002, 5, 788-797. 
3. Maier, D.A.; Brennan, A.L.; Jiang, S.; Binder-Scholl, G.K.; Lee, G.; Plesa, G.; Zheng, Z.; Cotte, J.; Carpenito, C.; Wood, T.; et al. Efficient clinical scale gene modification via zinc finger nuclease-targeted disruption of the hiv co-receptor CCR5. Hum. Gene Ther. 2013, 24, 245-258.

4. Holt, N.; Wang, J.; Kim, K.; Friedman, G.; Wang, X.; Taupin, V.; Crooks, G.M.; Kohn, D.B.; Gregory, P.D.; Holmes, M.C.; et al. Human hematopoietic stem/progenitor cells modified by zincfinger nucleases targeted to CCR5 control HIV-1 in vivo. Nat. Biotechnol. 2010, 28, 839-847.

5. Podsakoff, G.M.; Engel, B.C.; Carbonaro, D.A.; Choi, C.; Smogorzewska, E.M.; Bauer, G.; Selander, D.; Csik, S.; Wilson, K.; Betts, M.R.; et al. Selective survival of peripheral blood lymphocytes in children with HIV-1 following delivery of an anti-HIV gene to bone marrow CD34 ${ }^{+}$cells. Mol. Ther. 2005, 12, 77-86.

6. Von Laer, D.; Hasselmann, S.; Hasselmann, K. Gene therapy for HIV infection: What does it need to make it work? J. Gene Med. 2006, 8, 658-667.

7. Macpherson, J.L.; Boyd, M.P.; Arndt, A.J.; Todd, A.V.; Fanning, G.C.; Ely, J.A.; Elliott, F.; Knop, A.; Raponi, M.; Murray, J.; et al. Long-term survival and concomitant gene expression of ribozyme-transduced CD4 ${ }^{+}$T-lymphocytes in HIV-infected patients. J. Gene Med. 2005, 7, 552-564.

8. Tebas, P.; Stein, D.; Binder-Scholl, G.; Mukherjee, R.; Brady, T.; Rebello, T.; Humeau, L.; Kalos, M.; Papasavvas, E.; Montaner, L.J.; et al. Antiviral effects of autologous CD4 T cells genetically modified with a conditionally replicating lentiviral vector expressing long antisense to HIV. Blood 2013, 121, 1524-1533.

9. Van Lunzen, J.; Glaunsinger, T.; Stahmer, I.; von Baehr, V.; Baum, C.; Schilz, A.; Kuehlcke, K.; Naundorf, S.; Martinius, H.; Hermann, F.; et al. Transfer of autologous gene-modified T cells in HIV-infected patients with advanced immunodeficiency and drug-resistant virus. Mol. Ther. 2007, 15, 1024-1033.

10. Morgan, R.A.; Walker, R.; Carter, C.S.; Natarajan, V.; Tavel, J.A.; Bechtel, C.; Herpin, B.; Muul, L.; Zheng, Z.; Jagannatha, S.; et al. Preferential survival of CD4 ${ }^{+} \mathrm{T}$ lymphocytes engineered with anti-human immunodeficiency virus (HIV) genes in HIV-infected individuals. Hum. Gene Ther. 2005, 16, 1065-1074.

11. Ao, Z.; Wang, X.; Bello, A.; Jayappa, K.D.; Yu, Z.; Fowke, K.; He, X.; Chen, X.; Li, J.; Kobinger, G.; et al. Characterization of anti-HIV activity mediated by R88-APOBEC3G mutant fusion proteins in $\mathrm{CD}^{+} \mathrm{T}$ cells, peripheral blood mononuclear cells, and macrophages. Hum. Gene Ther. 2011, 22, 1225-1237.

12. Gupta, R.K.; Hué, S.; Schaller, T.; Verschoor, E.; Pillay, D.; Towers, G.J. Mutation of a single residue renders human tetherin resistant to HIV-1 Vpu-mediated depletion. PLoS Pathog. 2009, 5, doi:10.1371/journal.ppat.1000443

13. Neagu, M.R.; Ziegler, P.; Pertel, T.; Strambio-De-Castillia, C.; Grütter, C.; Martinetti, G.; Mazzucchelli, L.; Grütter, M.; Manz, M.G.; Luban, J. Potent inhibition of HIV-1 by TRIM5cyclophilin fusion proteins engineered from human components. J. Clin. Invest. 2009, 119, 3035-3047.

14. Walker, J.E.; Chen, R.X.; McGee, J.; Nacey, C.; Pollard, R.B.; Abedi, M.; Bauer, G.; Nolta, J.A.; Anderson, J.S. Generation of an HIV-1 resistant immune system with CD34 ${ }^{+}$HSCS transduced with a triple combination anti-HIV lentiviral vector. J. Virol. 2012, doi:10.1128/JVI.06300-11. 
15. Bieniasz, P.D. Intrinsic immunity: A front-line defense against viral attack. Nat. Immunol. 2004, 5, 1109-1115.

16. Blanco-Melo, D.; Venkatesh, S.; Bieniasz, P.D. Intrinsic cellular defenses against human immunodeficiency viruses. Immunity 2012, 37, 399-411.

17. Hultquist, J.F.; Lengyel, J.A.; Refsland, E.W.; LaRue, R.S.; Lackey, L.; Brown, W.L.; Harris, R.S. Human and rhesus APOBEC3D, APOBEC3F, APOBEC3G, and APOBEC3H demonstrate a conserved capacity to restrict Vif-deficient HIV-1. J. Virol. 2011, 85, 11220-11234.

18. Le Tortorec, A.; Willey, S.; Neil, S.J. Antiviral inhibition of enveloped virus release by tetherin/bst-2: Action and counteraction. Viruses 2011, 3, 520-540.

19. Si, Z.; Vandegraaff, N.; O’Huigin, C.; Song, B.; Yuan, W.; Xu, C.; Perron, M.; Li, X.; Marasco, W.A.; Engelman, A.; et al. Evolution of a cytoplasmic tripartite motif (TRIM) protein in cows that restricts retroviral infection. Proc. Natl. Acad. Sci. USA 2006, 103, 7454-7459.

20. Ylinen, L.M.J.; Keckesova, Z.; Webb, B.L.J.; Gifford, R.J.M.; Smith, T.P.L.; Towers, G.J. Isolation of an active Lv1 gene from cattle indicates that tripartite motif protein-mediated innate immunity to retroviral infection is widespread among mammals. J. Virol. 2006, 80, 7332-7338.

21. Gabuzda, D.H.; Lawrence, K.; Langhoff, E.; Terwilliger, E.; Dorfman, T.; Haseltine, W.A.; Sodroski, J. Role of Vif in replication of human immunodeficiency virus type 1 in $\mathrm{CD}^{+} \mathrm{T}$ lymphocytes. J. Virol. 1992, 66, 6489-6495.

22. Sheehy, A.M.; Gaddis, N.C.; Choi, J.D.; Malim, M.H. Isolation of a human gene that inhibits HIV-1 infection and is suppressed by the viral Vif protein. Nature 2002, 418, 646-650.

23. Harris, R.S.; Petersen-Mahrt, S.K.; Neuberger, M.S. RNA editing enzyme APOBEC1 and some of its homologs can act as DNA mutators. Mol. Cell 2002, 10, 1247-1253.

24. Mangeat, B.; Turelli, P.; Caron, G.; Friedli, M.; Perrin, L.; Trono, D. Broad antiretroviral defence by human APOBEC3G through lethal editing of nascent reverse transcripts. Nature 2003, 424, 99-103.

25. Zhang, H.; Yang, B.; Pomerantz, R.J.; Zhang, C.; Arunachalam, S.C.; Gao, L. The cytidine deaminase CEM15 induces hypermutation in newly synthesized HIV-1 DNA. Nature 2003, 424, 94-98.

26. Zennou, V.; Perez-Caballero, D.; Gottlinger, H.; Bieniasz, P.D. APOBEC3G incorporation into human immunodeficiency virus type 1 particles. J.Virol. 2004, 78, 12058-12061.

27. Khan, M.A.; Kao, S.; Miyagi, E.; Takeuchi, H.; Goila-Gaur, R.; Opi, S.; Gipson, C.L.; Parslow, T.G.; Ly, H.; Strebel, K. Viral rna is required for the association of APOBEC3G with human immunodeficiency virus type 1 nucleoprotein complexes. J. Virol. 2005, 79, 5870-5874.

28. Newman, E.N.C.; Holmes, R.K.; Craig, H.M.; Klein, K.C.; Lingappa, J.R.; Malim, M.H.; Sheehy, A.M. Antiviral function of APOBEC3G can be dissociated from cytidine deaminase activity. Curr. Biol. 2005, 15, 166-170.

29. Schrofelbauer, B.; Chen, D.; Landau, N.R. A single amino acid of APOBEC3G controls its species-specific interaction with virion infectivity factor (Vif). Proc. Natl. Acad. Sci. USA 2004, 101, 3927-3932.

30. Xu, H.; Svarovskaia, E.S.; Barr, R.; Zhang, Y.; Khan, M.A.; Strebel, K.; Pathak, V.K. A single amino acid substitution in human APOBEC3G antiretroviral enzyme confers resistance to HIV-1 virion infectivity factor-induced depletion. Proc. Natl. Acad. Sci. USA 2004, 101, 5652-5657. 
31. Ao, Z.; Yu, Z.; Wang, L.; Zheng, Y.; Yao, X. Vpr14-88-Apobec3G fusion protein is efficiently incorporated into Vif-positive HIV-1 particles and inhibits viral infection. PLoS One 2008, 3, doi:10.1371/journal.pone.0001995.

32. Kim, E.-Y.; Bhattacharya, T.; Kunstman, K.; Swantek, P.; Koning, F.A.; Malim, M.H.; Wolinsky, S.M. Human Apobec3G-mediated editing can promote HIV-1 sequence diversification and accelerate adaptation to selective pressure. J. Virol. 2010, 84, 10402-10405.

33. Fourati, S.; Malet, I.; Binka, M.; Boukobza, S.; Wirden, M.; Sayon, S.; Simon, A.; Katlama, C.; Simon, V.; Calvez, V.; et al. Partially active HIV-1 Vif alleles facilitate viral escape from specific antiretrovirals. AIDS 2010, 24, 2313-2321.

34. Neil, S.J.D.; Zang, T.; Bieniasz, P.D. Tetherin inhibits retrovirus release and is antagonized by HIV-1 Vpu. Nature 2008, 451, 425-430.

35. Van Damme, N.; Goff, D.; Katsura, C.; Jorgenson, R.L.; Mitchell, R.; Johnson, M.C.; Stephens, E.B.; Guatelli, J. The interferon-induced protein BST-2 restricts HIV-1 release and is downregulated from the cell surface by the viral Vpu protein. Cell Host Microbe 2008, 3, 245-252.

36. Kupzig, S.; Korolchuk, V.; Rollason, R.; Sugden, A.; Wilde, A.; Banting, G. BST-2/HM1.24 is a raft-associated apical membrane protein with an unusual topology. Traffic 2003, 4, 694-709.

37. Erikson, E.; Adam, T.; Schmidt, S.; Lehmann-Koch, J.; Over, B.; Goffinet, C.; Harter, C.; Bekeredjian-Ding, I.; Sertel, S.; Lasitschka, F.; et al. In vivo expression profile of the antiviral restriction factor and tumor-targeting antigen CD317/BST-2/HM1.24/tetherin in humans. Proc. Natl. Acad. Sci. USA 2011, 108, 13688-13693.

38. Douglas, J.L.; Viswanathan, K.; McCarroll, M.N.; Gustin, J.K.; Früh, K.; Moses, A.V. Vpu directs the degradation of the human immunodeficiency virus restriction factor BST-2/tetherin via a $\beta$ TrcP-dependent mechanism. J. Virol. 2009, 83, 7931-7947.

39. Mitchell, R.S.; Katsura, C.; Skasko, M.A.; Fitzpatrick, K.; Lau, D.; Ruiz, A.; Stephens, E.B.; Margottin-Goguet, F.; Benarous, R.; Guatelli, J.C. Vpu antagonizes BST-2-mediated restriction of HIV-1 release via beta-TrcP and endo-lysosomal trafficking. PLoS Pathog. 2009, 5, e1000450.

40. Lv, M.; Wang, J.; Zhu, Y.; Wang, X.; Zuo, T.; Liu, D.; Zhang, J.; Wu, J.; Zhang, H.; Kong, W.; et al. Overexpression of inactive tetherin delGPI mutant inhibits HIV-1 Vpu-mediated antagonism of endogenous tetherin. FEBS Lett. 2013, 587, 37-43.

41. Jia, B.; Serra-Moreno, R.; Neidermyer, W.; Rahmberg, A.; Mackey, J.; Fofana, I.B.; Johnson, W.E.; Westmoreland, S.; Evans, D.T. Species-specific activity of SIV nef and HIV-1 Vpu in overcoming restriction by tetherin/BST2. PLoS Pathog. 2009, 5, e1000429.

42. Gupta, R.K.; Mlcochova, P.; Pelchen-Matthews, A.; Petit, S.J.; Mattiuzzo, G.; Pillay, D.; Takeuchi, Y.; Marsh, M.; Towers, G.J. Simian immunodeficiency virus envelope glycoprotein counteracts tetherin/BST-2/CD317 by intracellular sequestration. Proc. Natl. Acad. Sci. USA 2009, 106, 20889-20894.

43. Le Tortorec, A.; Neil, S.J. Antagonism to and intracellular sequestration of human tetherin by the human immunodeficiency virus type 2 envelope glycoprotein. J. Virol. 2009, 83, 11966-11978.

44. Rice, G.I.; Bond, J.; Asipu, A.; Brunette, R.L.; Manfield, I.W.; Carr, I.M.; Fuller, J.C.; Jackson, R.M.; Lamb, T.; Briggs, T.A.; et al. Mutations involved in Aicardi-Goutières syndrome implicate SAMHD1 as regulator of the innate immune response. Nat. Genet. 2009, 41, 829-832. 
45. Hrecka, K.; Hao, C.; Gierszewska, M.; Swanson, S.K.; Kesik-Brodacka, M.; Srivastava, S.; Florens, L.; Washburn, M.P.; Skowronski, J. Vpx relieves inhibition of HIV-1 infection of macrophages mediated by the samhd1 protein. Nature 2011, 474, 658-661.

46. Laguette, N.; Sobhian, B.; Casartelli, N.; Ringeard, M.; Chable-Bessia, C.; Ségéral, E.; Yatim, A.; Emiliani, S.; Schwartz, O.; Benkirane, M. SAMHD1 is the dendritic- and myeloid-cell-specific HIV-1 restriction factor counteracted by Vpx. Nature 2011, 474, 654-657.

47. Baldauf, H.-M.; Pan, X.; Erikson, E.; Schmidt, S.; Daddacha, W.; Burggraf, M.; Schenkova, K.; Ambiel, I.; Wabnitz, G.; Gramberg, T.; et al. Samhd1 restricts HIV-1 infection in resting CD4 ${ }^{+} \mathrm{T}$ cells. Nat. Med. 2012, 18, 1682-1687.

48. Descours, B.; Cribier, A.; Chable-Bessia, C.; Ayinde, D.; Rice, G.; Crow, Y.; Yatim, A.; Schwartz, O.; Laguette, N.; Benkirane, M. SAMHD1 restricts HIV-1 reverse transcription in quiescent CD4 ${ }^{+}$T-cells. Retrovirology 2012, 9, doi:10.1186/1742-4690-9-87.

49. Goldstone, D.C.; Ennis-Adeniran, V.; Hedden, J.J.; Groom, H.C.T.; Rice, G.I.; Christodoulou, E.; Walker, P.A.; Kelly, G.; Haire, L.F.; Yap, M.W.; et al. HIV-1 restriction factor SAMHD1 is a deoxynucleoside triphosphate triphosphohydrolase. Nature 2011, 480, 379-382.

50. Lahouassa, H.; Daddacha, W.; Hofmann, H.; Ayinde, D.; Logue, E.C.; Dragin, L.; Bloch, N.; Maudet, C.; Bertrand, M.; Gramberg, T.; et al. Samhd1 restricts the replication of human immunodeficiency virus type 1 by depleting the intracellular pool of deoxynucleoside triphosphates. Nat. Immunol. 2012, 13, 223-228.

51. Powell, R.D.; Holland, P.J.; Hollis, T.; Perrino, F.W. Aicardi-Goutieres syndrome gene and HIV-1 restriction factor SAMHD1 is a dGTP-regulated deoxynucleotide triphosphohydrolase. J. Biol. Chem. 2011, 286, 43596-43600.

52. Beloglazova, N.; Flick, R.; Tchigvintsev, A.; Brown, G.; Popovic, A.; Nocek, B.; Yakunin, A.F. Nuclease activity of the human SAMHD1 protein implicated in the Aicardi-Goutieres syndrome and HIV-1 restriction. J. Biol. Chem. 2013, 288, 8101-8110.

53. Cribier, A.; Descours, B.; Valadão, A.L.C.; Laguette, N.; Benkirane, M. Phosphorylation of SAMHD1 by cyclin A2/Cdk1 regulates its restriction activity toward HIV-1. Cell Rep. 2013, 3, 1036-1043.

54. White, T.E.; Brandariz-Nuñez, A.; Valle-Casuso, J.C.; Amie, S.; Nguyen, L.A.; Kim, B.; Tuzova, M.; Diaz-Griffero, F. The retroviral restriction ability of SAMHD1, but not its deoxynucleotide triphosphohydrolase activity, is regulated by phosphorylation. Cell Host Microbe 2013, 13, 441-451.

55. Stremlau, M.; Owens, C.M.; Perron, M.J.; Kiessling, M.; Autissier, P.; Sodroski, J. The cytoplasmic body component TRIM5 $\alpha$ restricts HIV-1 infection in old world monkeys. Nature 2004, 427, $848-853$.

56. Hatziioannou, T.; Perez-Caballero, D.; Yang, A.; Cowan, S.; Bieniasz, P.D. Retrovirus resistance factors Ref1 and Lv1 are species-specific variants of TRIM5a. Proc. Natl. Acad. Sci. USA 2004, 101, 10774-10779.

57. Keckesova, Z.; Ylinen, L.M.J.; Towers, G.J. The human and African green monkey TRIM5 $\alpha$ genes encode Ref1 and Lv1 retroviral restriction factor activities. Proc. Natl. Acad. Sci. USA 2004, 101, 10780-10785. 
58. Towers, G.; Bock, M.; Martin, S.; Takeuchi, Y.; Stoye, J.P.; Danos, O. A conserved mechanism of retrovirus restriction in mammals. Proc. Natl. Acad. Sci. USA 2000, 97, 12295-12299.

59. Towers, G.; Collins, M.; Takeuchi, Y. Abrogation of Ref1 retrovirus restriction in human cells. J. Virol. 2002, 76, 2548-2550.

60. Hatziioannou, T.; Cowan, S.; Goff, S.P.; Bieniasz, P.D.; Towers, G.J. Restriction of multiple divergent retroviruses by Lv1 and Ref1. EMBO J. 2003, 22, 385-394.

61. Besnier, C.; Takeuchi, Y.; Towers, G. Restriction of lentivirus in monkeys. Proc. Natl. Acad. Sci. USA 2002, 99, 11920-11925.

62. Cowan, S.; Hatziioannou, T.; Cunningham, T.; Muesing, M.A.; Gottlinger, H.G.; Bieniasz, P.D. Cellular inhibitors with Fv1-like activity restrict human and simian immunodeficiency virus tropism. Proc. Natl. Acad. Sci. USA 2002, 99, 11914-11919.

63. Munk, C.; Brandt, S.M.; Lucero, G.; Landau, N.R. A dominant block to HIV-1 replication at reverse transcription in simian cells. Proc. Natl. Acad. Sci. USA 2002, 99, 13843-13848.

64. Nakayama, E.E.; Miyoshi, H.; Nagai, Y.; Shioda, T. A specific region of 37 amino acid residues in the SPRY (B30.2) domain of african green monkey TRIM5 $\alpha$ determines species-specific restriction of simian immunodeficiency virus SIVmac infection. J. Virol. 2005, 79, 8870-8877.

65. Perez-Caballero, D.; Hatziioannou, T.; Yang, A.; Cowan, S.; Bieniasz, P.D. Human tripartite motif $5 \alpha$ domains responsible for retrovirus restriction activity and specificity. J.Virol. 2005, 79, 8969-8978.

66. Stremlau, M.; Perron, M.; Welikala, S.; Sodroski, J. Species-specific variation in the B30.2 (SPRY) domain of TRIM5 $\alpha$ determines the potency of human immunodeficiency virus restriction. J. Virol. 2005, 79, 3139-3145.

67. Yap, M.W.; Nisole, S.; Stoye, J.P. A single amino acid change in the spry domain of human TRIM5 $\alpha$ leads to HIV-1 restriction. Curr. Biol. 2005, 15, 73-78.

68. Perez-Caballero, D.; Hatziioannou, T.; Yang, A.; Cowan, S.; Bieniasz, P.D. Human tripartite motif $5 \alpha$ domains responsible for retrovirus restriction activity and specificity. J. Virol. 2005, 79, 8969-8978.

69. Sawyer, S.L.; Wu, L.I.; Emerman, M.; Malik, H.S. Positive selection of primate TRIM5 $\alpha$ identifies a critical species-specific retroviral restriction domain. Proc. Natl. Acad. Sci. USA 2005, 102, 2832-2837.

70. Johnson, W.E.; Sawyer, S.L. Molecular evolution of the antiretroviral TRIM5 gene. Immunogenetics 2009, 61, 163-176.

71. Schaller, T.; Hué, S.p.; Towers, G.J. An active TRIM5 protein in rabbits indicates a common antiviral ancestor for mammalian TRIM5 proteins. J. Virol. 2007, 81, 11713-11721.

72. Fletcher, A.J.; Hué, S.; Schaller, T.; Pillay, D.; Towers, G.J. Hare TRIM5 $\alpha$ restricts divergent retroviruses and exhibits significant sequence variation from closely related lagomorpha TRIM5 genes. J. Virol. 2010, 84, 12463-12468.

73. Reymond, A.; Meroni, G.; Fantozzi, A.; Merla, G.; Cairo, S.; Luzi, L.; Riganelli, D.; Zanaria, E.; Messali, S.; Cainarca, S.; et al. The tripartite motif family identifies cell compartments. EMBO J. 2001, 20, 2140-2151.

74. Sawyer, S.L.; Emerman, M.; Malik, H.S. Discordant evolution of the adjacent antiretroviral genes TRIM22 and TRIM5 in mammals. PLoS Pathog. 2007, 3, e197. 
75. Asaoka, K.; Ikeda, K.; Hishinuma, T.; Horie-Inoue, K.; Takeda, S.; Inoue, S. A retrovirus restriction factor TRIM5 $\alpha$ is transcriptionally regulated by interferons. Biochem. Biophys. Res. Commun. 2005, 338, 1950-1956.

76. Ylinen, L.M.; Keckesova, Z.; Wilson, S.J.; Ranasinghe, S.; Towers, G.J. Differential restriction of human immunodeficiency virus type 2 and simian immunodeficiency virus SIVmac by trim5 $\alpha$ alleles. J. Virol. 2005, 79, 11580-11587.

77. Perron, M.J.; Stremlau, M.; Song, B.; Ulm, W.; Mulligan, R.C.; Sodroski, J. TRIM5 $\alpha$ mediates the postentry block to N-tropic murine leukemia viruses in human cells. Proc. Natl. Acad. Sci. USA 2004, 101, 11827-11832.

78. Newman, R.M.; Hall, L.; Connole, M.; Chen, G.L.; Sato, S.; Yuste, E.; Diehl, W.; Hunter, E.; Kaur, A.; Miller, G.M.; et al. Balancing selection and the evolution of functional polymorphism in old world monkey TRIM5a. Proc. Natl. Acad. Sci. USA 2006, 103, 19134-19139.

79. Wilson, S.J.; Webb, B.L.J.; Maplanka, C.; Newman, R.M.; Verschoor, E.J.; Heeney, J.L.; Towers, G.J. Rhesus macaque TRIM5 alleles have divergent antiretroviral specificities. J. Virol. 2008, 82, 7243-7247.

80. Speelmon, E.C.; Livingston-Rosanoff, D.; Li, S.S.; Vu, Q.; Bui, J.; Geraghty, D.E.; Zhao, L.P.; McElrath, M.J. Genetic association of the antiviral restriction factor TRIM5 $\alpha$ with human immunodeficiency virus type 1 infection. J. Virol. 2006, 80, 2463-2471.

81. Van Manen, D.L.; Rits, M.A.N.; Beugeling, C.; van Dort, K.; Schuitemaker, H.; Kootstra, N.A. The effect of TRIM5 polymorphisms on the clinical course of HIV-1 infection. PLoS Pathog. 2008, 4, e18.

82. Sewram, S.; Singh, R.; Kormuth, E.; Werner, L.; Mlisana, K.; Karim, S.S.A.; Ndung'u, T. Human TRIM5 $\alpha$ expression levels and reduced susceptibility to HIV-1 infection. J. Infect. Dis. 2009, 199, 1657-1663.

83. Anderson, J.; Akkina, R. Human immunodeficiency virus type 1 restriction by human-rhesus chimeric tripartite motif $5 \alpha$ (TRIM5 $\alpha$ ) in $\mathrm{CD} 4^{+}$cell-derived macrophages in vitro and in T cells in vivo in severe combined immunodeficient (SCID-hu) mice transplanted with human fetal tissue. Hum. Gene Ther. 2008, 19, 217-228.

84. Li, Y.; Li, X.; Stremlau, M.; Lee, M.; Sodroski, J. Removal of arginine 332 allows human TRIM5 $\alpha$ to bind human immunodeficiency virus capsids and to restrict infection. J. Virol. 2006, 80, 6738-6744.

85. Luban, J. Cyclophilin a, TRIM5, and resistance to human immunodeficiency virus type 1 infection. J.Virol. 2007, 81, 1054-1061.

86. Ganser-Pornillos, B.K.; Chandrasekaran, V.; Pornillos, O.; Sodroski, J.G.; Sundquist, W.I.; Yeager, M. Hexagonal assembly of a restricting TRIM5a protein. Proc. Natl. Acad. Sci. USA 2011, 108, 534-539.

87. Stremlau, M.; Perron, M.; Lee, M.; Li, Y.; Song, B.; Javanbakht, H.; az-Griffero, F.; Anderson, D.J.; Sundquist, W.I.; Sodroski, J. Specific recognition and accelerated uncoating of retroviral capsids by the TRIM5 $\alpha$ restriction factor. Proc. Natl. Acad. Sci. USA 2006, 103, 5514-5519.

88. Perron, M.J.; Stremlau, M.; Lee, M.; Javanbakht, H.; Song, B.; Sodroski, J. The human trim5alpha restriction factor mediates accelerated uncoating of the N-tropic murine leukemia virus capsid. J. Virol. 2007, 81, 2138-2148. 
89. Black, L.R.; Aiken, C. TRIM5 $\alpha$ disrupts the structure of assembled HIV-1 capsid complexes in vitro. J. Virol. 2010, 84, 6564-6569.

90. Zhao, G.; Ke, D.; Vu, T.; Ahn, J.; Shah, V.B.; Yang, R.; Aiken, C.; Charlton, L.M.; Gronenborn, A.M.; Zhang, P. Rhesus TRIM5 $\alpha$ disrupts the HIV-1 capsid at the inter-hexamer interfaces. PLoS Pathog. 2011, 7, e1002009.

91. Rold, C.J.; Aiken, C. Proteasomal degradation of TRIM5 $\alpha$ during retrovirus restriction. PLoS Pathog. 2008, 4, e1000074.

92. Anderson, J.L.; Campbell, E.M.; Wu, X.; Vandegraaff, N.; Engelman, A.; Hope, T.J. Proteasome inhibition reveals that a functional preintegration complex intermediate can be generated during restriction by diverse TRIM5 proteins. J. Virol. 2006, 80, 9754-9760.

93. Wu, X.; Anderson, J.L.; Campbell, E.M.; Joseph, A.M.; Hope, T.J. Proteasome inhibitors uncouple rhesus TRIM5 $\alpha$ restriction of HIV-1 reverse transcription and infection. Proc. Natl. Acad. Sci. USA 2006, 103, 7465-7470.

94. Campbell, E.M.; Perez, O.; Anderson, J.L.; Hope, T.J. Visualization of a proteasome-independent intermediate during restriction of HIV-1 by rhesus TRIM5 $\alpha$. J. Cell Biol. 2008, 180, 549-561.

95. Campbell, E.M.; Dodding, M.P.; Yap, M.W.; Wu, X.; Gallois-Montbrun, S.; Malim, M.H.; Stoye, J.P.; Hope, T.J. TRIM5 $\alpha$ cytoplasmic bodies are highly dynamic structures. Mol. Biol. Cell 2007, 18, 2102-2111.

96. Perez-Caballero, D.; Hatziioannou, T.; Zhang, F.; Cowan, S.; Bieniasz, P.D. Restriction of human immunodeficiency virus type 1 by TRIM-CypA occurs with rapid kinetics and independently of cytoplasmic bodies, ubiquitin, and proteasome activity. J. Virol. 2005, 79, 15567-15572.

97. Song, B.; Diaz-Griffero, F.; Park, D.H.; Rogers, T.; Stremlau, M.; Sodroski, J. TRIM5 $\alpha$ association with cytoplasmic bodies is not required for antiretroviral activity. Virology 2005, 343, 201-211.

98. Diaz-Griffero, F.; Gallo, D.E.; Hope, T.J.; Sodroski, J. Trafficking of some old world primate TRIM5 $\alpha$ proteins through the nucleus. Retrovirology 2011, 8, 38-38.

99. Tareen, S.U.; Emerman, M. Human TRIM5 $\alpha$ has additional activities that are uncoupled from retroviral capsid recognition. Virology 2011, 409, 113-120.

100. Pertel, T.; Hausmann, S.P.; Morger, D.; Züger, S.; Guerra, J.; Lascano, J.; Reinhard, C.; Santoni, F.A.; Uchil, P.D.; Chatel, L.; et al. TRIM5 is an innate immune sensor for the retrovirus capsid lattice. Nature 2011, 472, 361-365.

101. Gamble, T.R.; Vajdos, F.F.; Yoo, S.; Worthylake, D.K.; Houseweart, M.; Sundquist, W.I.; Hill, C.P. Crystal structure of human cyclophilin a bound to the amino-terminal domain of HIV-1 capsid. Cell 1996, 87, 1285-1294.

102. Bosco, D.A.; Eisenmesser, E.Z.; Pochapsky, S.; Sundquist, W.I.; Kern, D. Catalysis of cis/trans isomerization in native HIV-1 capsid by human cyclophilin A. Proc. Natl. Acad. Sci. USA 2002, 99, 5247-5252.

103. Gitti, R.K.; Lee, B.M.; Walker, J.; Summers, M.F.; Yoo, S.; Sundquist, W.I. Structure of the amino-terminal core domain of the HIV-1 capsid protein. Science 1996, 273, 231-235.

104. Yoo, S.; Myszka, D.G.; Yeh, C.; McMurray, M.; Hill, C.P.; Sundquist, W.I. Molecular recognition in the HIV-1 capsid/cyclophilin a complex. J. Mol. Biol. 1997, 269, 780-795. 
105. Franke, E.K.; Yuan, H.E.; Luban, J. Specific incorporation of cyclophilin a into HIV-1 virions. Nature 1994, 372, 359-362.

106. Thali, M.; Bukovsky, A.; Kondo, E.; Rosenwirth, B.; Walsh, C.T.; Sodroski, J.; Ýttlinger, H.G. Functional association of cyclophilin a with HIV-1 virions. Nature 1994, 372, 363-365.

107. Braaten, D.; Luban, J. Cyclophilin a regulates HIV-1 infectivity, as demonstrated by gene targeting in human T cells. EMBO J. 2001, 20, 1300-1309.

108. Sokolskaja, E.; Sayah, D.M.; Luban, J. Target cell cyclophilin a modulates human immunodeficiency virus type 1 infectivity. J.Virol. 2004, 78, 12800-12808.

109. Hatziioannou, T.; Perez-Caballero, D.; Cowan, S.; Bieniasz, P.D. Cyclophilin interactions with incoming human immunodeficiency virus type 1 capsids with opposing effects on infectivity in human cells. J. Virol. 2005, 79, 176-183.

110. Diaz-Griffero, F.; Vandegraaff, N.; Li, Y.; McGee-Estrada, K.; Stremlau, M.; Welikala, S.; Si, Z.; Engelman, A.; Sodroski, J. Requirements for capsid-binding and an effector function in trimcyp-mediated restriction of HIV-1. Virology 2006, 351, 404-419.

111. Lin, T.Y.; Emerman, M. Cyclophilin a interacts with diverse lentiviral capsids. Retrovirology 2006, 3, doi:10.1186/1742-4690-3-70.

112. Zhang, F.; Hatziioannou, T.; Perez-Caballero, D.; Derse, D.; Bieniasz, P.D. Antiretroviral potential of human tripartite motif-5 and related proteins. Virology 2006, 353, 396-409.

113. Braaten, D.; Franke, E.K.; Luban, J. Cyclophilin a is required for an early step in the life cycle of human immunodeficiency virus type 1 before the initiation of reverse transcription. J. Virol. 1996, 70, 3551-3560.

114. Li, Y.; Kar, A.K.; Sodroski, J. Target cell type-dependent modulation of human immunodeficiency virus type 1 capsid disassembly by cyclophilin A. J. Virol. 2009, 83, 10951-10962.

115. Towers, G.J. The control of viral infection by tripartite motif proteins and cyclophilin A. Retrovirology 2007, 4, doi:10.1186/1742-4690-4-40.

116. Sokolskaja, E.; Berthoux, L.; Luban, J. Cyclophilin A and TRIM5 $\alpha$ independently regulate human immunodeficiency virus type 1 infectivity in human cells. J. Virol. 2006, 80, 2855-2862.

117. Battivelli, E.; Lecossier, D.; Matsuoka, S.; Migraine, J.; Clavel, F.; Hance, A.J. Strain-specific differences in the impact of human TRIM5 $\alpha$, different TRIM5 $\alpha$ alleles, and the inhibition of capsid-cyclophilin a interactions on the infectivity of HIV-1. J. Virol. 2010, 84, 11010-11019.

118. Keckesova, Z.; Ylinen, L.M.; Towers, G.J. Cyclophilin A renders human immunodeficiency virus type 1 sensitive to old world monkey but not human TRIM5 $\alpha$ antiviral activity. J. Virol. 2006, 80, 4683-4690.

119. Towers, G.J.; Hatziioannou, T.; Cowan, S.; Goff, S.P.; Luban, J.; Bieniasz, P.D. Cyclophilin A modulates the sensitivity of HIV-1 to host restriction factors. Nat. Med. 2003, 9, 1138-1143.

120. Rasaiyaah, J.T.; Tan, C.P.; Fletcher, A.J.; Price, A.J.; Blondeau, C.; Hilditch, L.; Jacques, D.A.; Selwood, D.L.; James, L.C.; Noursadeghi, M.; Towers, G.J. HIV-1 evades innate immune recognition through specific co-factor recruitment. Nature 2013, doi:10.1038/nature12769.

121. Schaller, T.; Ocwieja, K.E.; Rasaiyaah, J.; Price, A.J.; Brady, T.L.; Roth, S.L.; Hué, S.; Fletcher, A.J.; Lee, K.; KewalRamani, V.N.; et al. HIV-1 capsid-cyclophilin interactions determine nuclear import pathway, integration targeting and replication efficiency. PLoS Pathog. 2011, 7, e1002439. 
122. Matreyek, K.A.; Yucel, S.S.; Li, X.; Engelman, A. Nucleoporin NUP153 phenylalanine-glycine motifs engage a common binding pocket within the HIV-1 capsid protein to mediate lentiviral infectivity. PLoS Pathog 2013, 9, e1003693.

123. Nisole, S.; Lynch, C.; Stoye, J.P.; Yap, M.W. A TRIM5-cyclophilin a fusion protein found in owl monkey kidney cells can restrict HIV-1. Proc. Natl. Acad. Sci. USA 2004, 101, 13324-13328.

124. Sayah, D.M.; Sokolskaja, E.; Berthoux, L.; Luban, J. Cyclophilin A retrotransposition into TRIM5 explains owl monkey resistance to HIV-1. Nature 2004, 430, 569-573.

125. Brennan, G.; Kozyrev, Y.; Hu, S.L. Trimcyp expression in old world primates macaca nemestrina and macaca fascicularis. Proc. Natl. Acad. Sci. USA 2008, 105, 3569-3574.

126. Newman, R.M.; Hall, L.; Kirmaier, A.; Pozzi, L.A.; Pery, E.; Farzan, M.; O’Neil, S.P.; Johnson, W. Evolution of a TRIM5-CypA splice isoform in old world monkeys. PLoS Pathog. 2008, 4, e1000003.

127. Langelier, C.R.; Sandrin, V.; Eckert, D.M.; Christensen, D.E.; Chandrasekaran, V.; Alam, S.L.; Aiken, C.; Olsen, J.C.; Kar, A.K.; Sodroski, J.G.; et al. Biochemical characterization of a recombinant TRIM5 $\alpha$ protein that restricts human immunodeficiency virus type 1 replication. J. Virol. 2008, 82, 11682-11694.

128. Wilson, S.J.; Webb, B.L.; Ylinen, L.M.; Verschoor, E.; Heeney, J.L.; Towers, G.J. Independent evolution of an antiviral TRIMCyp in rhesus macaques. Proc. Natl. Acad. Sci. USA 2008, 105, 3557-3562.

129. Price, A.J.; Marzetta, F.; Lammers, M.; Ylinen, L.M.J.; Schaller, T.; Wilson, S.J.; Towers, G.J.; James, L.C. Active site remodeling switches HIV specificity of antiretroviral TRIMCyp. Nat. Struct. Mol. Biol. 2009, 16, 1036-1042.

130. Ylinen, L.M.J.; Price, A.J.; Rasaiyaah, J.; Hué, S.; Rose, N.J.; Marzetta, F.; James, L.C.; Towers, G.J. Conformational adaptation of asian macaque TRIMCyp directs lineage specific antiviral activity. PLoS Pathog. 2010, 6, doi:10.1371/journal.ppat.1001062.

131. Malfavon-Borja, R.; Wu, L.I.; Emerman, M.; Malik, H.S. Birth, decay, and reconstruction of an ancient TRIMCyp gene fusion in primate genomes. Proc. Natl. Acad. Sci. USA 2013, 110, E583-E592.

132. Walker, J.E.; Chen, R.X.; McGee, J.; Nacey, C.; Pollard, R.B.; Abedi, M.; Bauer, G.; Nolta, J.A.; Anderson, J.S. Generation of an HIV-1-resistant immune system with CD34 ${ }^{+}$hematopoietic stem cells transduced with a triple-combination anti-HIV lentiviral vector. J. Virol. 2012, 86, 5719-5729.

133. Chan, E.; Schaller, T.; Eddaoudi, A.; Zhan, H.; Tan, C.P.; Jacobsen, M.; Thrasher, A.J.; Towers, G.J.; Qasim, W. Lentiviral gene therapy against human immunodeficiency virus type 1, using a novel human TRIM21-cyclophilin a restriction factor. Hum. Gene Ther. 2012, 23, 1176-1185.

134. Mallery, D.L.; McEwan, W.A.; Bidgood, S.R.; Towers, G.J.; Johnson, C.M.; James, L.C. Antibodies mediate intracellular immunity through tripartite motif-containing 21 (TRIM21). Proc. Natl. Acad. Sci. USA 2010, 107, 19985-19990.

135. McEwan, W.A.; Tam, J.C.; Watkinson, R.E.; Bidgood, S.R.; Mallery, D.L.; James, L.C. Intracellular antibody-bound pathogens stimulate immune signaling via the Fc receptor TRIM21. Nat. Immunol. 2013, 14, 327-336.

136. Yap, M.W.; Dodding, M.P.; Stoye, J.P. TRIM-cyclophilin a fusion proteins can restrict human immunodeficiency virus type 1 infection at two distinct phases in the viral life cycle. J. Virol. 2006, 80, 4061-4067. 
137. Schaller, T.; Ylinen, L.M.; Webb, B.L.; Singh, S.; Towers, G.J. Fusion of cyclophilin a to Fv1 enables cyclosporine-sensitive restriction of human and feline immunodeficiency viruses. J. Virol. 2007, 81, 10055-10063.

138. Biffi, A.; Montini, E.; Lorioli, L.; Cesani, M.; Fumagalli, F.; Plati, T.; Baldoli, C.; Martino, S.; Calabria, A.; Canale, S.; et al. Lentiviral hematopoietic stem cell gene therapy benefits metachromatic leukodystrophy. Science 2013, 341, doi:10.1126/science.1233158.

139. Aiuti, A.; Biasco, L.; Scaramuzza, S.; Ferrua, F.; Cicalese, M.P.; Baricordi, C.; Dionisio, F.; Calabria, A.; Giannelli, S.; Castiello, M.C.; et al. Lentiviral hematopoietic stem cell gene therapy in patients with wiskott-aldrich syndrome. Science 2013, 341, doi:10.1126/science.1233151.

140. Hütter, G.; Nowak, D.; Mossner, M.; Ganepola, S.; Müssig, A.; Allers, K.; Schneider, T.; Hofmann, J.; Kücherer, C.; Blau, O.; et al. Long-term control of HIV by CCR5 delta32/delta32 stem-cell transplantation. N. Engl. J. Med. 2009, 360, 692-698.

(C) 2014 by the authors; licensee MDPI, Basel, Switzerland. This article is an open access article distributed under the terms and conditions of the Creative Commons Attribution license (http://creativecommons.org/licenses/by/3.0/). 